\title{
Not All Antibodies Are Created Equal: Factors That Influence Antibody Mediated Rejection
}

\author{
Carrie L. Butler, Nicole M. Valenzuela, Kimberly A. Thomas, and Elaine F. Reed \\ Department of Pathology and Laboratory Medicine, David Geffen School of Medicine, University of California, Los Angeles, CA, USA \\ Correspondence should be addressed to Elaine F. Reed; ereed@mednet.ucla.edu
}

Received 16 November 2016; Revised 17 February 2017; Accepted 23 February 2017; Published 8 March 2017

Academic Editor: Junchao Cai

Copyright ( 2017 Carrie L. Butler et al. This is an open access article distributed under the Creative Commons Attribution License, which permits unrestricted use, distribution, and reproduction in any medium, provided the original work is properly cited.

\begin{abstract}
Consistent with Dr. Paul Terasaki's "humoral theory of rejection" numerous studies have shown that HLA antibodies can cause acute and chronic antibody mediated rejection (AMR) and decreased graft survival. New evidence also supports a role for antibodies to non-HLA antigens in AMR and allograft injury. Despite the remarkable efforts by leaders in the field who pioneered single antigen bead technology for detection of donor specific antibodies, a considerable amount of work is still needed to better define the antibody attributes that are associated with AMR pathology. This review highlights what is currently known about the clinical context of pre and posttransplant antibodies, antibody characteristics that influence AMR, and the paths after donor specific antibody production (no rejection, subclinical rejection, and clinical dysfunction with AMR).
\end{abstract}

\section{Introduction}

Antibody mediated rejection (AMR) is a major contributor to rejection risk and allograft loss in solid organ transplantation $[1,2]$. AMR diagnostic criteria were first established in cardiac [3] and renal [4] transplantation and have recently been described for pancreas [5] and lung transplantation [6] and, although historically controversial, are proposed for liver [7] and intestinal [8] allografts as well. AMR incidence is approximately $10-20 \%$ in cardiac [9], 5-8\% in renal [10], $4-25 \%$ in lung [11, 12], and $24 \%$ in liver [13] transplant. Central features of AMR pathology include endothelial cell (EC) swelling, microvascular inflammation, and intravascular CD68+ macrophages with or without complement deposition. Antibodies, most notably those specific for human leukocyte antigen (HLA), mediate effector functions that manifest in the histopathology of AMR. HLA are the most polymorphic genes in the human genome and as such result in the development of alloantibodies when an exact match is not found, as the donor allograft contains foreign HLA. The presence of HLA donor specific antibodies (DSA) is highly indicative of AMR $[14,15]$. The advent of HLA DSA detection methods [16-18] has led to studies identifying the correlation of HLA DSA with more severe AMR, yet we still are unable to fully predict how harmful or "pathogenic"
DSA will be. Further complicating matters is the recent association of non-HLA antibodies with allograft rejection. A greater understanding of all the factors (donor and recipient characteristics and antibody attributes) that contribute to rejection is needed to enhance the predictive performance of risk assessments and better determine which patients are at an increased risk for AMR. This review will address the clinical context of pre- and posttransplant antibodies, HLA and non-HLA antibody characteristics that influence AMR, and the three outcomes (stable function, subclinical dysfunction, and clinical dysfunction with AMR) mediated by these antibodies.

\section{HLA Antibodies}

2.1. Pretransplant. Pretransplant sensitization can occur from prior transplants, blood transfusions, pregnancy, and mechanical assist devices (in heart failure) resulting in autoantibody formation. Allosensitization affects approximately 6-9\% of cardiac transplant candidates $[19,20]$ and $23 \%$ of renal transplant candidates prior to transplantation [21]. Patients who are presensitized have a significantly increased risk of developing AMR within the first three years after cardiac transplantation compared to those who are not sensitized [22]. 
Preformed HLA antibodies were also associated with AMR in kidney transplantation [23-25]. In a multicenter prospective clinical study, kidney allograft recipients with HLA antibodies were associated with an increased risk for graft failure 1 year after transplant [26]. In liver transplantation, preformed DSA has been associated with an increased risk of AMR $[7,27]$. Roux et al. found that preformed HLA DSA was associated with AMR, chronic dysfunction, and graft loss in a lung transplant cohort with 2-year follow-up [28].

2.2. Posttransplant. After transplantation, $24 \%$ of renal allograft recipients will develop de novo HLA DSA within ten years [29] and approximately $25 \%$ of cardiac allograft recipients will develop de novo HLA DSA within thirteen years [30]. Nearly one-third of low risk patients (first transplant, no DSA) develop de novo DSA by 12 years after transplant [31]. De novo DSA development rates are $25-50 \%$ after lung transplantation [6]. Additionally, long-term posttransplant follow-up of renal allograft recipients revealed a significant decline in the ten-year graft survival rate for recipients that developed de novo antibodies to HLA [32] compared to those that did not. Smith et al. reported that de novo and persistent DSA postcardiac transplant were associated with poor long-term patient survival [30]. De novo DSA in liver transplantation is also associated with $\operatorname{AMR}[27,33]$. Many studies in lung transplant do not address the temporal timing of DSA potentially because AMR has only recently been recognized in lung transplantation and the presence of circulating DSA (regardless of preformed or de novo) is a key diagnostic standard [6]. However, multiple studies have found an associated risk of AMR in patients with DSA in lung transplantation $[12,34]$.

\section{Non-HLA Antibodies}

3.1. Pretransplant. Non-HLA antigens have been shown to be expressed intracellularly, on the EC cell surface and to apoptotic cells [35]. Non-HLA antibodies can occur independently or can occur concurrently with HLA DSA within patients, sometimes creating a synergistic effect on the allograft [36]. Additionally, antibodies specific for angiotensin II type 1 receptor $\left(\mathrm{AT}_{1} \mathrm{R}\right)$ can precede de novo HLA DSA [36]. $\mathrm{AT}_{1} \mathrm{R}$ antibodies are autoantibodies. Pretransplant $\mathrm{AT}_{1} \mathrm{R}$ antibodies have been associated with AMR in kidney $[37,38]$ and heart [39] transplant recipients. MICA is a polymorphic nonclassical class I antigen that is closely linked to the HLA$B$ locus and is upregulated on endothelial and epithelial cells during cellular stress. Antibodies to MICA have been found in the serum of renal [40] transplant recipients and were associated with humoral rejection and graft loss. Perlecan is a heparin sulfate proteoglycan that is cleaved by cathepsin-L to form a C-terminal fragment called LG3, as it contains three laminin-like globular domains. Pretransplant LG3 antibodies have been found to be associated with acute vascular rejection independent of HLA DSA in kidney transplant recipients [41]. Patients with preformed collagen V and K $\alpha$-tubulin antibodies were at an increased risk of developing HLA
DSA, and bronchiolitis obliterans syndrome (BOS) [42], a manifestation of chronic rejection.

3.2. Posttransplant. $\mathrm{AT}_{1} \mathrm{R}$ antibodies are associated with AMR in cardiac [39] and renal [43-45] transplantation. Others have reported that concomitant HLA and $\mathrm{AT}_{1} \mathrm{R}$ antibodies in renal and cardiac transplantation increased the risk of AMR and decreased graft survival [36, 46]. Endothelin type $\mathrm{A}$ receptor $\left(\mathrm{ET}_{\mathrm{A}} \mathrm{R}\right)$ antibodies have also been reported in renal [47] and cardiac [39] transplantation. Antibodies against $\mathrm{AT}_{1} \mathrm{R}$ and $\mathrm{ET}_{\mathrm{A}} \mathrm{R}$ have also been shown to be increased in lung allograft recipients with cystic fibrosis [48]. Antibodies to MICA have been found in the serum of renal [40] and cardiac [49] transplant recipients, although conflicting evidence exists about the independent pathogenic role of MICA in chronic rejection [50,51]. Posttransplant LG3 antibodies have been found in renal transplant recipients $[41,52]$. Collagen $\mathrm{V}(\mathrm{Col} \mathrm{V})$ is an extracellular matrix protein expressed on the lung interstitium and lung epithelial cells. Col V antibodies have been found in sera from lung allograft recipients diagnosed with bronchiolitis obliterans syndrome (BOS), a manifestation of chronic rejection [53, 54]. Additionally, Col V autoantibodies are associated with AMR and cardiac allograft vasculopathy (CAV) in cardiac transplant recipients [55] and transplant glomerulopathy in renal allograft recipients [56].

\section{Three Paths after DSA}

Patients with DSA do not represent a uniform category. Patients are either transplanted with no allosensitization, with HLA antibodies but no donor specific antibodies (3rd party), or with preformed DSA. Additionally, patients with a history of sensitization may never have circulating DSA detected in screening protocols, even though they have formed $\mathrm{T}$ and $\mathrm{B}$ cell alloimmune memory. Despite strong evidence that DSA are associated with increased rejection incidence and reduced graft survival, it is unknown why a subset of patients with DSA does not experience poorer graft outcomes in these studies $[31,57,58]$. This creates uncertainty about how to manage patients who exhibit DSA on routine monitoring but have no clinical signs of graft dysfunction or whether a preformed HLA DSA of a certain strength or titer can be safely crossed. Extraordinarily high levels of DSA ( $>10,000 \mathrm{MFI}$ in our experience), especially to HLA class I antigens, have been shown to be cytotoxic and place patients at risk of hyperacute rejection via complement activation; such strong DSA are typically avoided with the exception of liver transplantation $[59,60]$. Transplant recipients with DSA can exhibit overt rejection (acute or chronic) with clinical dysfunction, indolent dysfunction (slow decline in graft function) with subclinical rejection on protocol biopsy, or stable function and normal biopsy (Figure 1).

4.1. Clinical Dysfunction with AMR. Evidence of clinical allograft dysfunction is an important consideration in diagnosis of symptomatic (clinical) AMR. Nearly half of patients transplanted with preformed DSA experienced AMR, compared 

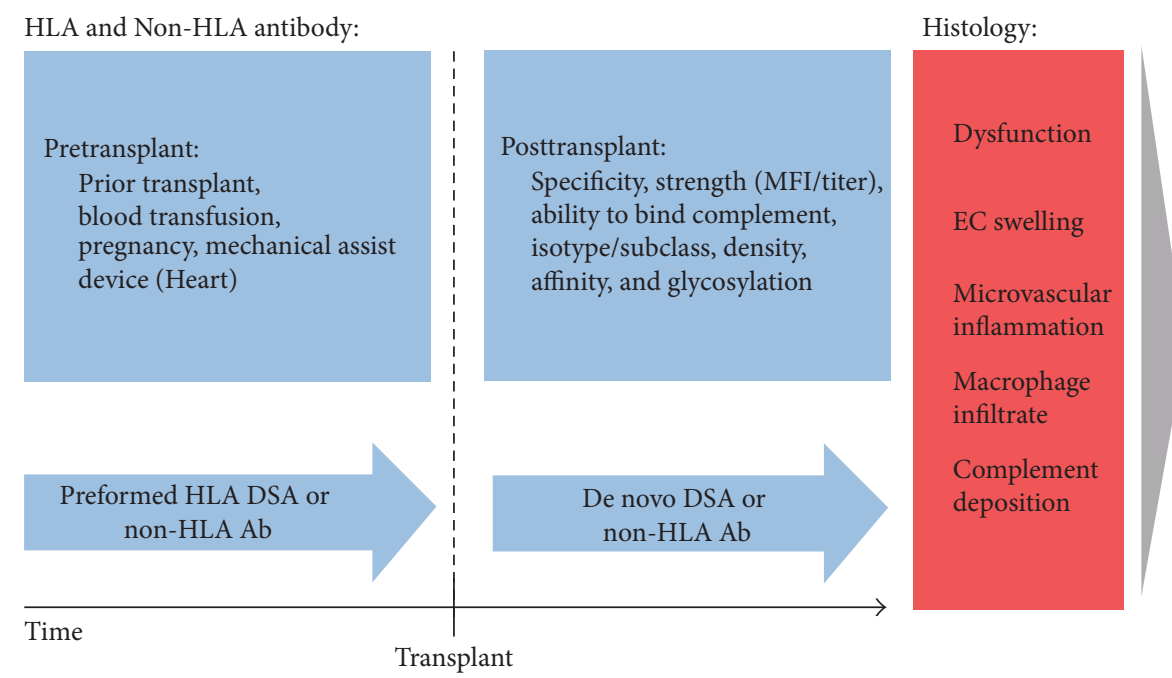

Outcomes:

(1) Stable function:

(i) DSA+

(ii) $\mathrm{IgG} 2, \mathrm{IgG} 4$

(iii) $\mathrm{C} 1 \mathrm{q}-, \mathrm{C} 4 \mathrm{~d}-$

(2) Subclinical AMR:

(i) DSA+

(ii) IgG2, IgG4

(iii) $\mathrm{C} 1 \mathrm{q}-, \mathrm{C} 4 \mathrm{~d} \pm$

(3) Clinical dysfunction:

(i) Acute AMR

(a) DSA+

(b) IgG3, IgG1

(c) $\mathrm{Clq}+, \mathrm{C} 4 \mathrm{~d}+$

(ii) Chronic AMR

(a) $\mathrm{DSA}+$

(b) IgG2, IgG4

(c) $\mathrm{C} 1 \mathrm{q} \pm, \mathrm{C} 4 \mathrm{~d} \pm$

FIGURE 1: Factors influencing AMR. Schematic of the antibody components that influence AMR's pathogenesis. Depicted are the antibody factors (blue) that influence AMR pathology (shown in red). Antibody factors influencing AMR include sensitization pretransplant and antibody attributes such as specificity, ability to bind complement, isotype/subclass, strength (MFI/titer), density, affinity, and glycosylation. AMR histology (red) includes graft dysfunction, endothelial cell (EC) swelling, microvascular inflammation, and macrophage infiltrate and can occur with or without complement deposition. The three outcomes after DSA include stable function, subclinical AMR and clinical dysfunction with AMR (either acute or chronic). Stable function in the presence of DSA is typically seen in those patients with IgG2/IgG4 antibodies that do not show signs of complement binding antibodies (Clq-, C4d-). Subclinical AMR is typically seen in those patients with IgG2/IgG4 antibodies that may show signs of complement binding antibodies (Clq-, C4d \pm ). Clinical dysfunction with AMR can be grouped into acute or chronic AMR. Acute AMR is typically seen in those patients with IgG3/IgG1 antibodies that are complement binding antibodies $(\mathrm{Clq}+, \mathrm{C} 4 \mathrm{~d}+)$. Chronic AMR is typically seen in those patients with $\mathrm{IgG} 2 / \mathrm{IgG} 4$ antibodies that may or may not include complement binding antibodies $(\mathrm{Clq} \pm, \mathrm{C} 4 \mathrm{~d} \pm)$.

with less than $1 \%$ in those without pretransplant DSA [61]. Of renal transplant recipients with preformed DSA who developed AMR, the majority were flow crossmatch positive [61-63]. De novo DSA is often observed at the same time as clinical dysfunction [32], and the vast majority of patients presenting with allograft functional impairment and dnDSA were nonadherent [32]. Thus patients are more likely to develop AMR if their DSA is strong enough to cause a positive flow crossmatch and more likely to experience graft dysfunction if they were medication nonadherent. In the long-term, patients experiencing clinical dysfunction with AMR have the worst 5-year graft survival compared with TCMR or no rejection [58].

4.2. Subclinical $A M R$. Studies evaluating protocol biopsies have reported a high incidence of subclinical AMR that is likely missed by monitoring strategies that biopsy only for cause. One-year surveillance biopsies in DSA+ patients with stable function nonetheless often revealed C4d deposition and peritubular capillaritis [32], indicative of "smoldering" inflammation not present in patients without DSA. Similarly, Loupy et al. showed that $14 \%$ of clinically stable renal transplant recipients had evidence of subclinical AMR on one-year surveillance biopsy [57]. The majority of these patients had performed DSA. Importantly, these studies have demonstrated that patients with subclinical AMR (i.e., no acute dysfunction) fare significantly worse than their DSA negative counterparts [57], with faster decline in GFR of renal allografts $[31,57,61]$ and higher rates of CAV in cardiac allografts [64-66]. Renal transplant recipients with subclinical AMR who received treatment with plasmapheresis unfortunately had comparable outcomes to those who were not untreated, and both had a significant decrement in 5-year survival compared with AMR-free controls [61]. Similarly, half of cardiac transplants that failed more than one year after transplant due to chronic rejection had a history of subclinical AMR [67]. While patients with clinically symptomatic AMR fare worse than those with subclinical AMR, both groups have significantly reduced 10 -year outcomes compared with stable, DSA negative patients [31].

4.3. DSA with Stable Function and No Rejection. Intriguingly, up to half of patients with preformed DSA did not have rejection, subclinical AMR, or otherwise, at the time of oneyear biopsy $[57,68]$. Approximately $20 \%$ of stable patients with no evidence of rejection on protocol biopsy also had DSA. Thus, a critical, yet unanswered, question is which patient, donor, and antibody characteristics might protect from rejection and graft dysfunction in the presence of DSA, a question which is addressed in part in the next section.

\section{Mechanisms of Antibody Mediated Graft Injury}

5.1. HLA Antibodies. Antibodies mediate allograft injury and contribute to graft pathology through three main types of 
effector functions: EC activation, complement activation, and leukocyte interaction/activation. Alterations in these effector functions modulate rejection severity. Antibody characteristics, such as titer, isotype/subclass, glycosylation, and affinity, can influence these effector functions. The interface between the allograft and its recipient is the thin layer of donor EC lining the walls of the blood vessels supplying nutrients to the allograft. Gene profiling studies of renal [69-71] and cardiac biopsies [72] undergoing AMR identified EC activation as a significant contributor to graft pathology. Crosslinking of HLA expressed on the surface of EC by DSA triggers a series of intracellular signaling events and activation of immune responses, which are manifested in the histopathological findings in AMR pathology [73]. DSA binding to HLA induces EC activation, resulting in P-selectin expression and mammalian target of rapamycin (mTOR) dependent cellular migration, proliferation, and protein synthesis [74-77]. Positive staining of phosphorylated mTOR signaling proteins including S6 kinase and S6 ribosomal protein in the capillary EC of endomyocardial biopsies strongly correlated with diagnosis of AMR [78, 79]. EC activation facilitates chemokine expression leading to leukocyte recruitment to inflammatory sites [80]. In addition, increased EC and smooth muscle proliferation results in a thickening of the tunica intima [81], a hallmark of chronic AMR in all solid organ transplant patients [3]. Antibody titer affects EC signal transduction and subsequent EC activation, as increasing quantities of HLA antibody result in augmented FGFR expression and cellular proliferation [82], whereas decreased antibody titer results in upregulation of prosurvival genes and antiapoptotic proteins in EC [83]. An additional antibody-independent factor that influences HLA-mediated signaling is the density of HLA molecule expression on the EC surface. HLA antigen expression on graft endothelium is increased during allograft rejection in response to IFN $\gamma$ and induces CIITA activation and subsequent HLA Class II expression [84-87]. The density of HLA on the surface of EC directly affects the degree of DSA binding to the graft and downstream effector functions.

Although complement deposition is no longer necessary for AMR diagnosis, complement binding DSA increases a patient's risk for kidney allograft loss five years after transplant [88] and complement binding antibodies were more predictive, than HLA DSA alone, of an increased risk for AMR and decreased graft survival in cardiac transplant ten years after transplant [89]. Antibody isotype and subclass play a significant role in induction of the classical complement pathway, with IgM, IgG3, and IgG1 having the highest degree of complement activation [90]. Antibody affinity mediated by IgG hexamers has been shown to be more efficient than isolated IgG molecules at activating the complement cascade [91]. Complement binding is also increased when there is an increase in the amount of antibody bound to cells [92, 93]. High panel reactive antibodies (PRA) are associated with increased complement activation [92]. Lastly, polymorphisms within the complement genetic locus could potentially affect the degree of complement activation $[94,95]$, whereas differential expression of complement regulatory proteins by the donor tissue could also affect the response of endothelium to complement components [96]. With respect to the downstream effects of complement activation, Janewit et al. demonstrated that complement activation and deposition on EC resulted in noncanonical $\mathrm{NF} \kappa \mathrm{B}$ activation [97] whereas Cravedi et al. highlighted a role for complement activation in promotion of a Thl response during alloimmune reactions [98]. Taken together, this information highlights the potential contributions of DSA on complement activation and promotion of alloimmunity.

Leukocyte recruitment and activation are a common histological feature of AMR. Macrophage infiltration is observed in heart [3] and renal [99] AMR and predicts a worse outcome [100]. Neutrophil recruitment is seen in lung transplantation and intragraft natural killer (NK) cells have been identified by molecular microscopy techniques in renal [71] and cardiac biopsies [72] diagnosed with AMR. IgG subclass dictates Fc receptor binding affinity $[101,102]$, thereby influencing leukocyte recruitment. Several studies have attempted to characterize the repertoire of DSA immunoglobulin subclasses in transplant recipients and correlate them with allograft outcomes. Their results have suggested that IgG3 DSA are a driver of acute AMR [103, 104], while IgG4 correlates more closely with subclinical AMR [105] and chronic rejection $[106,107]$. Moreover, different terminal moieties in the Fc glycan of IgG have been demonstrated to change the inflammatory nature of antibodies. Sialylated IgG promotes a more tolerant environment, whereas glycans with terminal galactose residues are affiliated with a proinflammatory response [108]. Altered P-selectin expression allows for an increase in leukocyte recruitment [77 depending on subclass, by engaging Fc $\gamma$ Rs, 109], a common histological feature across solid organ transplant $[3,6,109]$. DSA also facilitated NK cellmediated antibody-dependent cellular cytotoxicity (ADCC) in an IFN $\gamma$ and cell-contact dependent manner [110]. Collectively, the effector functions of DSA, while multifactorial themselves, are even more complex and multilayered when antibody characteristics are altered.

5.2. Non-HLA Antibodies. There is less mechanistic data for non-HLA antibodies in the pathogenesis of AMR. However, non-HLA antibodies can also mediate EC activation and complement activation and leukocyte interaction/activation. Non-HLA antibodies that activate EC can increase the expression of HLA class I and II and have been shown to develop independently or in conjunction with HLA DSA $[36,111] . \mathrm{AT}_{1} \mathrm{R}$ antibodies mediate endothelial cell activation and vasoconstriction by binding to the second extracellular loop of the $\mathrm{AT}_{1} \mathrm{R}$ protein and act as an angiotensin II agonist promoting downstream activation of AP-1 and NF- $\kappa \mathrm{B}$ [112]. $\mathrm{AT}_{1} \mathrm{R}$ and $\mathrm{ET}_{\mathrm{A}} \mathrm{R}$ antibodies frequently occur together in patient sera [111]; but there are no studies linking their pathologic mechanism. DSA bound to EC are also capable of activating the classical complement pathway, resulting in detection of $\mathrm{C} 4 \mathrm{~d}$ deposition along the capillary walls within allograft biopsies [113-115]. C4d deposition in graft histology has only been detected in a subset of patients with $\mathrm{AT}_{1} \mathrm{R}$ antibodies suggesting that the mechanism of injury for $\mathrm{AT}_{1} \mathrm{R}$ antibodies is not the complement pathway [43, $44,112]$. However, other non-HLA antibodies such as MICA 
can activate complement [116]. Evidence suggests that Col V antibodies increase IL-17 and IFN $\gamma$ secreting T cells [117]. LG3 antibodies promote the migration of smooth muscle cells or mesenchymal stem cells to cause vascular injury [118].

Experimental models and clinical experience demonstrate that anti-donor HLA and non-HLA antibodies exhibit pathogenic functions through multiple mechanisms that likely have extensive crosstalk. AMR manifests as a broad spectrum both histologically and symptomatically. Across solid organs, the microvasculature is the principal target of antibody mediated injury. A single uniform approach to prevent graft injury and loss in the setting of donor specific antibodies will probably not be effective for all patients, and personalized therapies tailored to address unique patient and donor features will be needed to protect from AMR and chronic rejection. Non-HLA antibodies have also been associated with TCMR in renal transplantation [119] suggesting additional mechanisms of action that promote distinct graft pathology phenotypes compared to HLA DSA. While these histopathological features are diagnostically useful, they are an in situ readout of the downstream effects of DSA-mediated effector functions. Recent work is uncovering additional mechanisms by which DSA can mediate immune activation. Further studies are needed to delineate the crosstalk between HLA and non-HLA antibodies and their synergistic effect on graft injury and to assess their incidence across different organ types.

\section{Conclusions and Future Directions}

Collectively, data on antibody pathogenicity defined by the antibody specificity, isotype, and ability to activate EC and complement can lead to different effector functions that mediate different pathological outcomes. Further studies to clarify which HLA and non-HLA antibody attributes (strength, subclasses, glycosylation, and affinity) contribute to subclinical, acute, and chronic AMR would be useful in order to identify biomarkers of different outcomes. Employment of newer techniques, such as the "molecular microscope," can provide additional insight into the active transcriptome in the graft tissue, allowing a measurement of the local inflammation and the transcriptome signature for AMR [68]. Clinical research to determine how effective these parameters are at risk stratifying patients is needed. Enhanced understanding of the HLA and non-HLA mechanisms in allograft injury is needed to help identify additional therapeutic targets and further understand the potential synergistic relationship between them. Allograft rejection can occur throughout the lifetime of a transplanted organ and as such further understanding of the sensitization and pathologic mechanisms is needed to better risk stratify patients and achieve the goal of increasing long-term survival.

\section{Conflicts of Interest}

The authors declare that there are no conflicts of interest regarding the publication of this paper.

\section{Authors' Contributions}

Carrie L. Butler, Nicole M. Valenzuela, and Kimberly A. Thomas contributed equally to this work.

\section{References}

[1] P.-C. Lee, P. I. Terasaki, S. K. Takemoto et al., "All chronic rejection failures of kidney transplants were preceded by the development of HLA antibodies," Transplantation, vol. 74, no. 8, pp. 1192-1194, 2002.

[2] A. Ham, M. Kim, J. Y. Kim et al., "Selective deletion of the endothelial sphingosine-1-phosphate 1 receptor exacerbates kidney ischemia-reperfusion injury," Kidney International, vol. 85, no. 4, pp. 807-823, 2014.

[3] G. J. Berry, M. M. Burke, C. Andersen et al., "The 2013 international society for heart and lung transplantation working formulation for the standardization of nomenclature in the pathologic diagnosis of antibody-mediated rejection in heart transplantation," Journal of Heart and Lung Transplantation, vol. 32, no. 12, pp. 1147-1162, 2013.

[4] M. Haas, B. Sis, L. C. Racusen et al., "Banff 2013 meeting report: inclusion of C4d-negative antibody-mediated rejection and antibody-associated arterial lesions," American Journal of Transplantation, vol. 14, no. 2, pp. 272-283, 2014.

[5] C. B. Drachenberg, J. R. Torrealba, B. J. Nankivell et al., "Guidelines for the diagnosis of antibody-mediated rejection in pancreas allografts-updated Banff grading schema," American Journal of Transplantation, vol. 11, no. 9, pp. 1792-1802, 2011.

[6] D. J. Levine, A. R. Glanville, C. Aboyoun et al., "Antibodymediated rejection of the lung: a consensus report of the International Society for Heart and Lung Transplantation," Journal of Heart and Lung Transplantation, vol. 35, no. 4, pp. 397-406, 2016.

[7] J. G. O'Leary, S. Michelle Shiller, C. Bellamy et al., "Acute liver allograft antibody-mediated rejection: an inter-institutional study of significant histopathological features," Liver Transplantation, vol. 20, no. 10, pp. 1244-1255, 2014.

[8] G. S. Wu, "Updates on antibody-mediated rejection in intestinal transplantation," World Journal of Transplantation, vol. 6, no. 3, pp. 564-572, 2016.

[9] J. Kobashigawa, M. G. Crespo-Leiro, S. M. Ensminger et al., "Report from a consensus conference on antibody-mediated rejection in heart transplantation," The Journal of Heart and Lung Transplantation, vol. 30, no. 3, pp. 252-269, 2011.

[10] S. Lionaki, K. Panagiotellis, A. Iniotaki, and J. N. Boletis, "Incidence and clinical significance of de novo donor specific antibodies after kidney transplantation," Clinical and Developmental Immunology, vol. 2013, Article ID 849835, 9 pages, 2013.

[11] S. Otani, A. K. Davis, L. Cantwell et al., "Evolving experience of treating antibody-mediated rejection following lung transplantation," Transplant Immunology, vol. 31, no. 2, pp. 75-80, 2014.

[12] L. J. Lobo, R. M. Aris, J. Schmitz, and I. P. Neuringer, "Donorspecific antibodies are associated with antibody-mediated rejection, acute cellular rejection, bronchiolitis obliterans syndrome, and cystic fibrosis after lung transplantation," Journal of Heart and Lung Transplantation, vol. 32, no. 1, pp. 70-77, 2013.

[13] A. Del Bello, N. Congy-Jolivet, L. Rostaing, and N. Kamar, "Incidence of anti-HLA donor specific antibodies in livertransplant patients given mTOR inhibitors without calcineurin inhibitors," Journal of Hepatology, vol. 61, no. 4, pp. 963-965, 2014. 
[14] D. S. Nath, N. Angaswamy, H. I. Basha et al., "Donor-specific antibodies to human leukocyte antigens are associated with and precede antibodies to major histocompatibility complex class I-related chain A in antibody-mediated rejection and cardiac allograft vasculopathy after human cardiac transplantation," Human Immunology, vol. 71, no. 12, pp. 1191-1196, 2010.

[15] N. Lachmann, P. I. Terasaki, K. Budde et al., "Anti-human leukocyte antigen and donor-specific antibodies detected by luminex posttransplant serve as biomarkers for chronic rejection of renal allografts," Transplantation, vol. 87, no. 10, pp. 1505-1513, 2009.

[16] P. I. Terasaki and J. D. McClelland, "Microdroplet assay of human serum cytotoxins [38]," Nature, vol. 204, no. 4962, pp. 998-1000, 1964.

[17] P. I. Terasaki, D. L. Vredevoe, M. R. Mickey et al., "Serotyping for homotransplantation. VII. Selection of kidney donors for thirty-two recipients," Annals of the New York Academy of Sciences, vol. 129, pp. 500-520, 1966.

[18] P. I. Terasaki, M. Kreisler, and R. M. Mickey, "Presensitization and kidney transplant failures," Postgraduate Medical Journal, vol. 47, no. 544, pp. 89-100, 1971.

[19] L. U. Nwakanma, J. A. Williams, E. S. Weiss, S. D. Russell, W. A. Baumgartner, and J. V. Conte, "Influence of pretransplant panel-reactive antibody on outcomes in 8,160 heart transplant recipients in recent era," Annals of Thoracic Surgery, vol. 84, no. 5, pp. 1556-1563, 2007.

[20] R. John, K. Lietz, M. Schuster et al., "Immunologic sensitization in recipients of left ventricular assist devices," Journal of Thoracic and Cardiovascular Surgery, vol. 125, no. 3, pp. 578-591, 2003.

[21] S.-Y. Hung, T.-M. Lin, M.-Y. Chang et al., "Risk factors of sensitization to human leukocyte antigen in end-stage renal disease patients," Human Immunology, vol. 75, no. 6, pp. 531535, 2014.

[22] N. L. Reinsmoen, J. Patel, J. Mirocha et al., "Optimizing transplantation of sensitized heart candidates using 4 antibody detection assays to prioritize the assignment of unacceptable antigens," Journal of Heart and Lung Transplantation, vol. 35, no. 2, pp. 165-172, 2016.

[23] K. Marfo, A. Lu, M. Ling, and E. Akalin, "Desensitization protocols and their outcome," Clinical Journal of the American Society of Nephrology, vol. 6, no. 4, pp. 922-936, 2011.

[24] C. Lefaucheur, A. Loupy, G. S. Hill et al., "Preexisting donorspecific HLA antibodies predict outcome in kidney transplantation," Journal of the American Society of Nephrology, vol. 21, no. 8, pp. 1398-1406, 2010.

[25] A. Loupy and S. C. Jordan, "Transplantation: donor-specific HLA antibodies and renal allograft failure," Nature Reviews Nephrology, vol. 9, no. 3, pp. 130-131, 2013.

[26] P. I. Terasaki and M. Ozawa, "Predicting kidney graft failure by HLA antibodies: a prospective trial," American Journal of Transplantation, vol. 4, no. 3, pp. 438-443, 2004.

[27] A. J. Demetris, C. Bellamy, S. G. Hübscher et al., "2016 comprehensive update of the banff working group on liver allograft pathology: introduction of antibody-mediated rejection," American Journal of Transplantation, vol. 16, no. 10, pp. 28162835, 2016.

[28] A. Roux, I. Bendib Le Lan, S. Holifanjaniaina et al., "Antibodymediated rejection in lung transplantation: clinical outcomes and donor-specific antibody characteristics," American Journal of Transplantation, vol. 16, no. 4, pp. 1216-1228, 2016.

[29] M. J. Everly, "Incidence and hazards of alloantibodies in renal transplantation," Clinical Transplants, pp. 313-317, 2013.
[30] J. D. Smith, N. R. Banner, I. M. Hamour et al., "De novo donor HLA-specific antibodies after heart transplantation are an independent predictor of poor patient survival," American Journal of Transplantation, vol. 11, no. 2, pp. 312-319, 2011.

[31] C. Wiebe, I. W. Gibson, T. D. Blydt-Hansen et al., "Rates and determinants of progression to graft failure in kidney allograft recipients with de novo donor-specific antibody," American Journal of Transplantation, vol. 15, no. 11, pp. 2921-2930, 2015.

[32] C. Wiebe, I. W. Gibson, T. D. Blydt-Hansen et al., "Evolution and clinical pathologic correlations of de novo donor-specific HLA antibody post kidney transplant," American Journal of Transplantation, vol. 12, no. 5, pp. 1157-1167, 2012.

[33] A. Del Bello, N. Congy-Jolivet, M. Danjoux, F. Muscari, and N. Kamar, "Donor-specific antibodies and liver transplantation," Human Immunology, vol. 77, no. 11, pp. 1063-1070, 2016.

[34] C. A. Witt, J. P. Gaut, R. D. Yusen et al., "Acute antibodymediated rejection after lung transplantation," Journal of Heart and Lung Transplantation, vol. 32, no. 10, pp. 1034-1040, 2013.

[35] L. A. Michielsen, A. D. van Zuilen, M. M. Krebber, M. C. Verhaar, and H. G. Otten, "Clinical value of non-HLA antibodies in kidney transplantation: still an enigma?" Transplantation Reviews, vol. 30, no. 4, pp. 195-202, 2016.

[36] M. Taniguchi, L. M. Rebellato, J. Cai et al., "Higher risk of kidney graft failure in the presence of anti-angiotensin II Type-1 receptor antibodies," American Journal of Transplantation, vol. 13, no. 10, pp. 2577-2589, 2013.

[37] J. W. In, H. Park, E. Y. Rho et al., "Anti-angiotensin type 1 receptor antibodies associated with antibody-mediated rejection in patients without preformed HLA-donor-specific antibody," Transplantation Proceedings, vol. 46, no. 10, pp. 3371-3374, 2014.

[38] J. Lee, K. H. Huh, Y. Park et al., "The clinicopathological relevance of pretransplant anti-angiotensin II type 1 receptor antibodies in renal transplantation," Nephrology Dialysis Transplantation, 2015.

[39] N. E. Hiemann, R. Meyer, E. Wellnhofer et al., "Non-HLA antibodies targeting vascular receptors enhance alloimmune response and microvasculopathy after heart transplantation," Transplantation, vol. 94, no. 9, pp. 919-924, 2012.

[40] S. Sumitran-Holgersson, H. E. Wilczek, J. Holgersson, and K. Soderstrom, "Identification of the nonclassical HLA molecules, mica, as targets for humoral immunity associated with irreversible rejection of kidney allografts," Transplantation, vol. 74, no. 2, pp. 268-277, 2002.

[41] H. Cardinal, M. Dieudé, N. Brassard et al., "Antiperlecan antibodies are novel accelerators of immune-mediated vascular injury," American Journal of Transplantation, vol. 13, no. 4, pp. 861-874, 2013.

[42] R. R. Hachem, V. Tiriveedhi, G. A. Patterson, A. Aloush, E. P. Trulock, and T. Mohanakumar, "Antibodies to K- $\alpha 1$ tubulin and collagen $\mathrm{v}$ are associated with chronic rejection after lung transplantation," American Journal of Transplantation, vol. 12, no. 8, pp. 2164-2171, 2012.

[43] A. Fuss, C. M. Hope, S. Deayton et al., "C4d-negative antibodymediated rejection with high anti-angiotensin II type i receptor antibodies in absence of donor-specific antibodies," Nephrology, vol. 20, no. 7, pp. 467-473, 2015.

[44] N. L. Reinsmoen, C.-H. Lai, H. Heidecke et al., "Anti-angiotensin type 1 receptor antibodies associated with antibody mediated rejection in donor HLA antibody negative patients," Transplantation, vol. 90, no. 12, pp. 1473-1477, 2010.

[45] M. H. Pearl, R. K. Leuchter, E. F. Reed, Q. Zhang, R. B. Ettenger, and E. W. Tsai, "Accelerated rejection, thrombosis, and graft 
failure with angiotensin II type 1 receptor antibodies," Pediatric Nephrology, vol. 30, no. 8, pp. 1371-1374, 2015.

[46] N. L. Reinsmoen, C.-H. Lai, J. Mirocha et al., "Increased negative impact of donor HLA-specific together with nonHLA-specific antibodies on graft outcome," Transplantation, vol. 97, no. 5, pp. 595-601, 2014.

[47] M. Banasik, M. Boratyńska, K. Kościelska-Kasprzak et al., “The impact of non-HLA antibodies directed against endothelin-1 type A receptors (ETAR) on early renal transplant outcomes," Transplant Immunology, vol. 30, no. 1, pp. 24-29, 2014.

[48] K. Budding, E. A. van de Graaf, T. Hoefnagel et al., "AntiETAR and anti-AT1R autoantibodies are elevated in patients with endstage cystic fibrosis," Journal of Cystic Fibrosis, vol. 14, no. 1, pp. 42-45, 2015.

[49] Q. Zhang, J. M. Cecka, D. W. Gjertson et al., "HLA and MICA: targets of antibody-mediated rejection in heart transplantation," Transplantation, vol. 91, no. 10, pp. 1153-1158, 2011.

[50] A. Lemy, M. Andrien, A. Lionet et al., "Posttransplant major histocompatibility complex class I chain-related gene A antibodies and long-term graft outcomes in a multicenter cohort of 779 kidney transplant recipients," Transplantation, vol. 93, no. 12, pp. 1258-1264, 2012.

[51] J. D. Smith, V. M. Brunner, S. Jigjidsuren et al., "Lack of effect of MICA antibodies on graft survival following heart transplantation," American Journal of Transplantation, vol. 9, no. 8, pp. 1912-1919, 2009.

[52] M. Soulez, E.-A. Pilon, M. Dieudé et al., “The perlecan fragment LG3 is a novel regulator of obliterative remodeling associated with allograft vascular rejection," Circulation Research, vol. 110, no. 1, pp. 94-104, 2012.

[53] V. Tiriveedhi, N. Angaswamy, D. Brand et al., "A shift in the collagen $\mathrm{V}$ antigenic epitope leads to $\mathrm{T}$ helper phenotype switch and immune response to self-antigen leading to chronic lung allograft rejection," Clinical and Experimental Immunology, vol. 167, no. 1, pp. 158-168, 2012.

[54] W. J. Burlingham, R. B. Love, E. Jankowska-Gan et al., "IL-17dependent cellular immunity to collagen type $\mathrm{V}$ predisposes to obliterative bronchiolitis in human lung transplants," Journal of Clinical Investigation, vol. 117, no. 11, pp. 3498-3506, 2007.

[55] D. S. Nath, V. Tiriveedhi, H. I. Basha et al., "A role for antibodies to human leukocyte antigens, collagen- $\mathrm{V}$, and $\mathrm{K}-\alpha 1-$ tubulin in antibody-mediated rejection and cardiac allograft vasculopathy," Transplantation, vol. 91, no. 9, pp. 1036-1043, 2011.

[56] N. Angaswamy, C. Klein, V. Tiriveedhi et al., "Immune responses to collagen-IV and fibronectin in renal transplant recipients with transplant glomerulopathy," American Journal of Transplantation, vol. 14, no. 3, pp. 685-693, 2014.

[57] A. Loupy, D. Vernerey, C. Tinel et al., "Subclinical rejection phenotypes at 1 year post-transplant and outcome of kidney allografts," Journal of the American Society of Nephrology, vol. 26, no. 7, pp. 1721-1731, 2015.

[58] C. Lefaucheur, A. Loupy, D. Vernerey et al., "Antibody-mediated vascular rejection of kidney allografts: A Population-based Study," The Lancet, vol. 381, no. 9863, pp. 313-319, 2013.

[59] W. C. Goggins, R. A. Fisher, P. M. Kimball et al., "The impact of a positive crossmatch upon outcome after liver transplantation," Transplantation, vol. 62, no. 12, pp. 1794-1798, 1996.

[60] M. Castillo-Rama, M. J. Castro, I. Bernardo et al., "Preformed antibodies detected by cytotoxic assay or multibead array decrease liver allograft survival: role of human leukocyte antigen compatibility," Liver Transplantation, vol. 14, no. 4, pp. 554$562,2008$.

[61] B. J. Orandi, E. H. K. Chow, A. Hsu et al., "Quantifying renal allograft loss following early antibody-mediated rejection," American Journal of Transplantation, vol. 15, no. 2, pp. 489-498, 2015.

[62] P. Amico, P. Hirt-Minkowski, G. Hönger et al., "Risk stratification by the virtual crossmatch: a prospective study in 233 renal transplantations," Transplant International, vol. 24, no. 6, pp. 560-569, 2011.

[63] M. Haas, R. A. Montgomery, D. L. Segev et al., "Subclinical acute antibody-mediated rejection in positive crossmatch renal allografts," American Journal of Transplantation, vol. 7, no. 3, pp. 576-585, 2007.

[64] P. J. Michaels, M. L. Espejo, J. Kobashigawa et al., "Humoral rejection in cardiac transplantation: risk factors, hemodynamic consequences and relationship to transplant coronary artery disease," Journal of Heart and Lung Transplantation, vol. 22, no. 1, pp. 58-69, 2003.

[65] G. W. Wu, J. A. Kobashigawa, M. C. Fishbein et al., "Asymptomatic antibody-mediated rejection after heart transplantation predicts poor outcomes," Journal of Heart and Lung Transplantation, vol. 28, no. 5, pp. 417-422, 2009.

[66] A. G. Kfoury, M. E. H. Hammond, G. L. Snow et al., "Cardiovascular mortality among heart transplant recipients with asymptomatic antibody-mediated or stable mixed cellular and antibody-mediated rejection," Journal of Heart and Lung Transplantation, vol. 28, no. 8, pp. 781-784, 2009.

[67] A. Loupy, C. Toquet, P. Rouvier et al., "Late failing heart allografts: pathology of cardiac allograft vasculopathy and association with antibody-mediated rejection," American Journal of Transplantation, vol. 16, no. 1, pp. 111-120, 2016.

[68] A. Loupy, C. Lefaucheur, D. Vernerey et al., "Molecular microscope strategy to improve risk stratification in early antibodymediated kidney allograft rejection," Journal of the American Society of Nephrology, vol. 25, no. 10, pp. 2267-2277, 2014.

[69] J. Sellarés, J. Reeve, A. Loupy et al., "Molecular diagnosis of antibody-mediated rejection in human kidney transplants," American Journal of Transplantation, vol. 13, no. 4, pp. 971-983, 2013.

[70] G. Einecke, B. Sis, J. Reeve et al., "Antibody-mediated microcirculation injury is the major cause of late kidney transplant failure," American Journal of Transplantation, vol. 9, no. 11, pp. 2520-2531, 2009.

[71] P. F. Halloran, A. B. Pereira, J. Chang et al., "Microarray diagnosis of antibody-mediated rejection in kidney transplant biopsies: an international prospective study (INTERCOM)," American Journal of Transplantation, vol. 13, no. 11, pp. 2865$2874,2013$.

[72] A. Loupy, J. P. Duong Van Huyen, L. Hidalgo et al., "Gene expression profiling for the identification and classification of antibody-mediated heart rejection," Circulation, vol. 135, no. 10, pp. 917-935, 2017.

[73] K. A. Thomas, N. M. Valenzuela, and E. F. Reed, "The perfect storm: HLA antibodies, complement, $\mathrm{Fc} \gamma$ Rs, and endothelium in transplant rejection," Trends in Molecular Medicine, vol. 21, no. 5, pp. 319-329, 2015.

[74] X. Zhang, E. Rozengurt, and E. F. Reed, "HLA Class I molecules partner with integrin $\beta 4$ to stimulate endothelial cell proliferation and migration," Science Signaling, vol. 3, no. 149, article no. ra85, 2010. 
[75] N. M. Valenzuela, J. T. McNamara, and E. F. Reed, “Antibodymediated graft injury: complement-dependent and complement-independent mechanisms," Current Opinion in Organ Transplantation, vol. 19, no. 1, pp. 33-40, 2014.

[76] P. T. Jindra, Y.-P. Jin, E. Rozengurt, and E. F. Reed, "HLA class I antibody-mediated endothelial cell proliferation via the mTOR pathway," Journal of Immunology, vol. 180, no. 4, pp. 2357-2366, 2008.

[77] N. M. Valenzuela, A. Mulder, and E. F. Reed, "HLA class I antibodies trigger increased adherence of monocytes to endothelial cells by eliciting an increase in endothelial P-selectin and, dependingon subclass, by engaging Fc $\gamma$ Rs," Journal of Immunology, vol. 190, no. 12, pp. 6635-6650, 2013.

[78] F. Li, J. Wei, N. M. Valenzuela et al., "Phosphorylated S6 kinase and S6 ribosomal protein are diagnostic markers of antibodymediated rejection in heart allografts," Journal of Heart and Lung Transplantation, vol. 34, no. 4, pp. 580-587, 2015.

[79] M. Tible, A. Loupy, D. Vernerey et al., "Pathologic classification of antibody-mediated rejection correlates with donor-specific antibodies and endothelial cell activation," Journal of Heart and Lung Transplantation, vol. 32, no. 8, pp. 769-776, 2013.

[80] J. S. Pober and W. C. Sessa, "Evolving functions of endothelial cells in inflammation," Nature Reviews Immunology, vol. 7, no. 10, pp. 803-815, 2007.

[81] S. Galvani, M. Trayssac, N. Augé et al., "A key role for matrix metalloproteinases and neutral sphingomyelinase-2 in transplant vasculopathy triggered by anti-HLA antibody," Circulation, vol. 124, no. 24, pp. 2725-2734, 2011.

[82] P. T. Jindra, X. Zhang, A. Mulder et al., "Anti-HLA antibodies can induce endothelial cell survival or proliferation depending on their concentration," Transplantation, vol. 82, supplement 1 , pp. S33-S35, 2006.

[83] Y.-P. Jin, M. C. Fishbein, J. W. Said et al., "Anti-HLA class I antibody-mediated activation of the PI3K/Akt signaling pathway and induction of Bcl-2 and Bcl-xL expression in endothelial cells," Human Immunology, vol. 65, no. 4, pp. 291-302, 2004.

[84] K. A. Thomas, N. M. Valenzuela, D. Gjertson et al., "An anti-C1s monoclonal, TNT003, inhibits complement activation induced by antibodies against HLA," American Journal of Transplantation, vol. 15, no. 8, pp. 2037-2049, 2015.

[85] V. K. R. Mannam, R. E. Lewis, and J. M. Cruse, "The fate of renal allografts hinges on responses of the microvascular endothelium," Experimental and Molecular Pathology, vol. 94, no. 2, pp. 398-411, 2013.

[86] K. A. Muczynski, D. M. Ekle, D. M. Coder, and S. K. Anderson, "Normal human kidney HLA-DR-expressing renal microvascular endothelial cells: characterization, isolation, and regulation of MHC class II expression," Journal of the American Society of Nephrology, vol. 14, no. 5, pp. 1336-1348, 2003.

[87] M. M. Sadeghi, A. Tiglio, K. Sadigh et al., "Inhibition of interferon- $\gamma$-mediated microvascular endothelial cell major histocompatibility complex class II gene activation by HMGCOA reductase inhibitorsl," Transplantation, vol. 71, no. 9, pp. 1262-1268, 2001.

[88] A. Loupy, C. Lefaucheur, D. Vernerey et al., "Complementbinding anti-HLA antibodies and kidney-allograft survival," New England Journal of Medicine, vol. 369, no. 13, pp. 1215-1226, 2013.

[89] E. K. Ho, E. R. Vasilescu, G. Vlad, C. C. Marboe, L. J. Addonizio, and N. Suciu-Foca, "HLA antibodies in pediatric heart transplantation," Pediatric Transplantation, vol. 15, no. 5, pp. 458-464, 2011.
[90] G. Vidarsson, G. Dekkers, and T. Rispens, "IgG subclasses and allotypes: from structure to effector functions," Frontiers in Immunology, vol. 5, article 520, 2014.

[91] C. A. Diebolder, F. J. Beurskens, R. N. De Jong et al., "Complement is activated by IgG hexamers assembled at the cell surface," Science, vol. 343, no. 6176, pp. 1260-1263, 2014.

[92] A. AlMahri, J. Holgersson, and M. Alheim, "Detection of complement-fixing and non-fixing antibodies specific for endothelial precursor cells and lymphocytes using flow cytometry," Tissue Antigens, vol. 80, no. 5, pp. 404-415, 2012.

[93] D. Jane-Wit, T. D. Manes, T. Yi et al., "Alloantibody and complement promote $\mathrm{T}$ cell-mediated cardiac allograft vasculopathy through noncanonical nuclear factor- $\kappa \mathrm{B}$ signaling in endothelial Cells," Circulation, vol. 128, no. 23, pp. 2504-2516, 2013.

[94] M. Varagunam, M. M. Yaqoob, B. Döhler, and G. Opelz, "C3 polymorphisms and allograft outcome in renal transplantation," New England Journal of Medicine, vol. 360, no. 9, pp. 874-880, 2009.

[95] J. P. Atkinson, D. R. Karp, E. P. Seeskin et al., "H-2 S region determined polymorphic variants of the $\mathrm{C} 4$, Slp, C2, and B complement proteins: a compilation," Immunogenetics, vol. 16, no. 6, pp. 617-623, 1982.

[96] R. Hamer, G. Molostvov, D. Lowe et al., "Human leukocyte antigen-specific antibodies and gamma-interferon stimulate human microvascular and glomerular endothelial cells to produce complement factor C4," Transplantation, vol. 93, no. 9, pp. 867-873, 2012.

[97] D. Jane-wit, Y. V. Surovtseva, L. Qin et al., "Complement membrane attack complexes activate noncanonical NF- $\kappa$ B by forming an $\mathrm{Akt}^{+} \mathrm{NIK}^{+}$signalosome on $\mathrm{Rab5}^{+}$endosomes," Proceedings of the National Academy of Sciences of the United States of America, vol. 112, no. 31, pp. 9686-9691, 2015.

[98] P. Cravedi, J. Leventhal, P. Lakhani, S. C. Ward, M. J. Donovan, and P. S. Heeger, "Immune cell-derived C3a and C5a costimulate human T cell alloimmunity," American Journal of Transplantation, vol. 13, no. 10, pp. 2530-2539, 2013.

[99] A. B. Magil and K. Tinckam, "Monocytes and peritubular capillary C4d deposition in acute renal allograft rejection," Kidney International, vol. 63, no. 5, pp. 1888-1893, 2003.

[100] K. J. Tinckam, O. Djurdjev, and A. B. Magil, "Glomerular monocytes predict worse outcomes after acute renal allograft rejection independent of C4d status," Kidney International, vol. 68, no. 4, pp. 1866-1874, 2005.

[101] P. Bruhns, "Properties of mouse and human IgG receptors and their contribution to disease models," Blood, vol. 119, no. 24, pp. 5640-5649, 2012.

[102] R. Shashidharamurthy, F. Zhang, A. Amano et al., "Dynamics of the interaction of human IgG subtype immune complexes with cells expressing $\mathrm{R}$ and $\mathrm{H}$ allelic forms of a low-affinity $\mathrm{Fc} \gamma$ receptor CD32A," The Journal of Immunology, vol. 183, no. 12, pp. 8216-8224, 2009.

[103] H. Kaneku, J. G. O’Leary, M. Taniguchi, B. M. Susskind, P. I. Terasaki, and G. B. Klintmalm, "Donor-specific human leukocyte antigen antibodies of the immunoglobulin G3 subclass are associated with Chronic rejection and graft loss after liver transplantation," Liver Transplantation, vol. 18, no. 8, pp. 984992, 2012.

[104] M.-L. Arnold, I.-S. Ntokou, I. I. N. Doxiadis, B. M. Spriewald, J. N. Boletis, and A. G. Iniotaki, "Donor-specific HLA antibodies: evaluating the risk for graft loss in renal transplant recipients with isotype switch from complement fixing IgG1/IgG3 to 
noncomplement fixing IgG2/IgG4 anti-HLA alloantibodies," Transplant International, vol. 27, no. 3, pp. 253-261, 2014.

[105] C. Lefaucheur, D. Viglietti, C. Bentlejewski et al., "IgG donorspecific anti-human HLA antibody subclasses and kidney allograft antibody-mediated injury," Journal of the American Society of Nephrology, vol. 27, no. 1, pp. 293-304, 2016.

[106] Z.-H. Gao, V. C. McAlister, J. R. Wright Jr., C. C. McAlister, K. Peltekian, and A. S. MacDonald, "Immunoglobulin-G subclass antidonor reactivity in transplant recipients," Liver Transplantation, vol. 10, no. 8, pp. 1055-1059, 2004.

[107] J. C. Cicciarelli, N. A. Lemp, Y. Chang et al., "Renal transplant patients biopsied for cause and tested for C4d, DSA, and IgG subclasses and Clq: which humoral markers improve diagnosis and outcomes?" Journal of Immunology Research, vol. 2017, Article ID 1652931, 14 pages, 2017.

[108] R. Goulabchand, T. Vincent, F. Batteux, J.-F. Eliaou, and P. Guilpain, "Impact of autoantibody glycosylation in autoimmune diseases," Autoimmunity Reviews, vol. 13, no. 7, pp. 742-750, 2014.

[109] M. Haas, "The revised (2013) banff classification for antibodymediated rejection of renal allografts: update, difficulties, and future considerations," American Journal of Transplantation, vol. 16, no. 5, pp. 1352-1357, 2016.

[110] C. M. Lin, R. J. Plenter, M. Coulombe, and R. G. Gill, "Interferon gamma and contact-dependent cytotoxicity are each rate limiting for natural killer cell-mediated antibody-dependent chronic rejection," American Journal of Transplantation, vol. 16, no. 11, pp. 3121-3130, 2016.

[111] D. Dragun, R. Catar, and A. Philippe, "Non-HLA antibodies against endothelial targets bridging allo- and autoimmunity," Kidney International, vol. 90, no. 2, pp. 280-288, 2016.

[112] D. Dragun, D. N. Müller, J. H. Bräsen et al., "Angiotensin II type 1-receptor activating antibodies in renal-allograft rejection," New England Journal of Medicine, vol. 352, no. 6, pp. 558-569, 2005.

[113] S. E. Fedson, S. S. Daniel, and A. N. Husain, "Immunohistochemistry staining of C4d to diagnose antibody-mediated rejection in cardiac transplantation," Journal of Heart and Lung Transplantation, vol. 27, no. 4, pp. 372-379, 2008.

[114] D. N. Ionescu, A. L. Girnita, A. Zeevi et al., "C4d deposition in lung allografts is associated with circulating anti-HLA alloantibody," Transplant Immunology, vol. 15, no. 1, pp. 63-68, 2005.

[115] M. L. Troxell, J. P. Higgins, and N. Kambham, "Evaluation of C4d staining in liver and small intestine allografts," Archives of Pathology and Laboratory Medicine, vol. 130, no. 10, pp. 14891496, 2006.

[116] E. Sánchez-Zapardiel, M. J. Castro-Panete, E. Mancebo et al., "Early renal graft function deterioration in recipients with preformed anti-MICA antibodies: partial contribution of complement-dependent cytotoxicity," Nephrology Dialysis Transplantation, vol. 31, no. 1, pp. 150-160, 2016.

[117] D. Saini, J. Weber, S. Ramachandran et al., "Alloimmunityinduced autoimmunity as a potential mechanism in the pathogenesis of chronic rejection of human lung allografts," Journal of Heart and Lung Transplantation, vol. 30, no. 6, pp. 624-631, 2011.

[118] E. A. Pilon, M. Dieudé, S. Qi et al., "The perlecan fragment LG3 regulates homing of mesenchymal stem cells and neointima formation during vascular rejection," American Journal of Transplantation, vol. 15, no. 5, pp. 1205-1218, 2015.
[119] A. M. Jackson, T. K. Sigdel, M. Delville et al., "Endothelial cell antibodies associated with novel targets and increased rejection," Journal of the American Society of Nephrology, vol. 26, no. 5, pp. 1161-1171, 2015. 


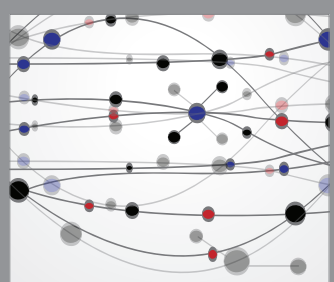

The Scientific World Journal
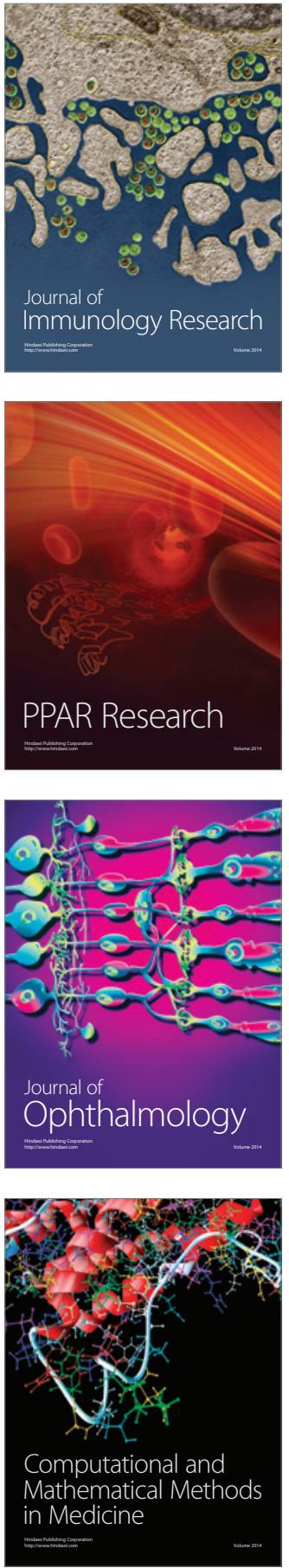

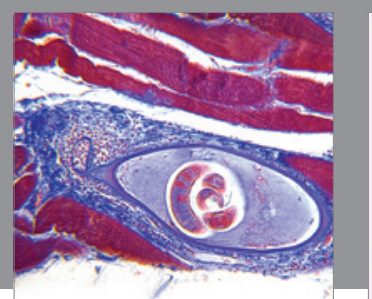

Gastroenterology Research and Practice
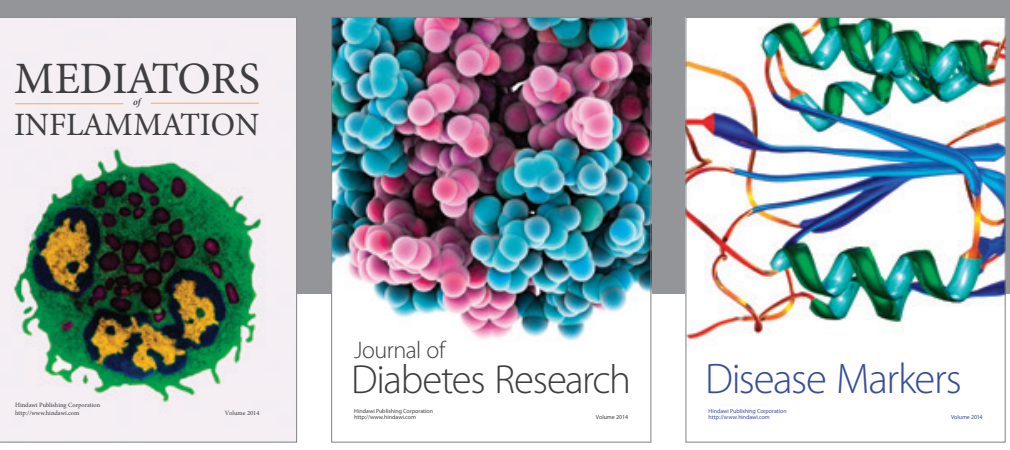

Disease Markers

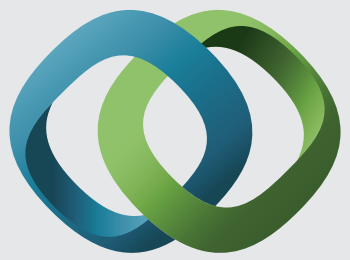

\section{Hindawi}

Submit your manuscripts at

https://www.hindawi.com
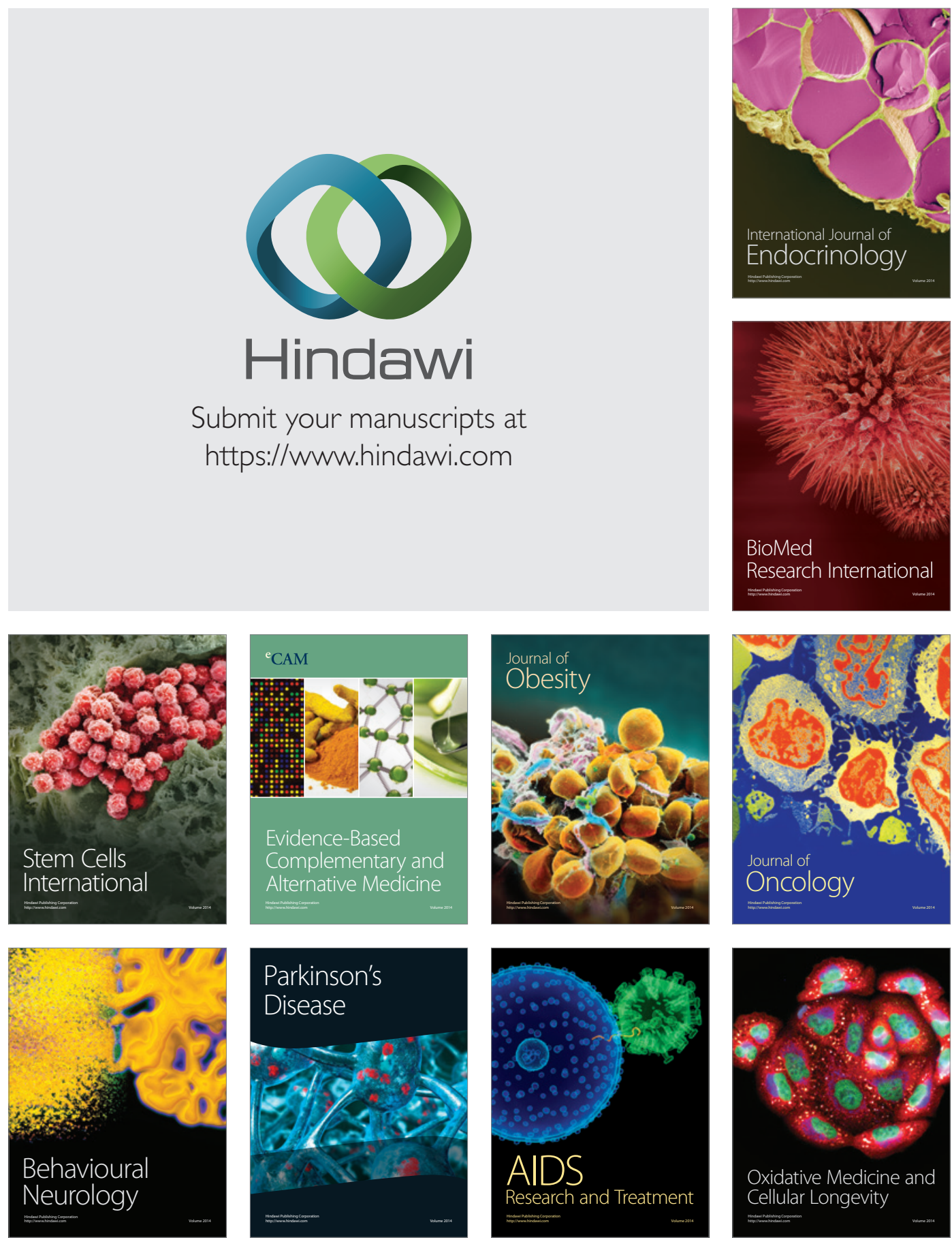